\title{
Gamma Knife radiosurgery: effect on corticotropin-secreting pituitary adenoma
}

\author{
Dan Nicolae Paduraru, ${ }^{1,2}$, Raluca Ciunt ${ }^{3}$, Andra Morar ${ }^{4}$, \\ Laura Maria Dragomir ${ }^{3}$, Carla Scânteie ${ }^{3}$, \\ Alexandra Bolocan ${ }^{1,2}$, Octavian Andronic ${ }^{1,2}$, \\ Cristina Ghervan ${ }^{3,5}$, Bogdan Socea ${ }^{2,6}$, \\ Mara Carsote ${ }^{7}$, Ana Valea ${ }^{3,5}$
}

1 General Surgery Department and Emergency III, University Emergency Hospital of Bucharest, ROMANIA

2 Carol Davila University of Medicine and Pharmacy, Bucharest, ROMANIA

3 Endocrinology Department, County Clinical Emergency Hospital, Cluj-Napoca, ROMANIA

${ }^{4}$ Clinical Hospital of Infectious Diseases, Cluj-Napoca, RomanIA

5 Iuliu Hatieganu University of Medicine and Pharmacy \& County Clinical Hospital, Cluj-Napoca, ROMANIA

${ }^{6}$ Clinical Emergency Hospital "Sf. Pantelimon", Bucharest, ROMANIA

${ }^{7}$ C.I. Parhon National Institute of Endocrinology, Bucharest, ROMANIA

\begin{abstract}
Introduction: Cushing's disease (CD) is a complex endocrine disorder characterized by an increased risk of recurrence and persistence of hypercortisolism after initial transsphenoidal adenomectomy, a situation requiring alternative therapeutic measures.

Case presentation: A 21-year-old female patient was admitted for weight gain with centripetal fat distribution, transient headache, hair thinning and psycho-emotional lability. Clinical examination revealed round facies, acne, purple-red striae, hirsutism with a Ferriman-Gallwey score of 20 . The hormonal profile revealed high serum cortisol (of $283.1 \mathrm{ng} / \mathrm{mL}$, normal:70-225 ng/mL) and high ACTH (Adrenocorticotropic Hormone) levels (of $260.6 \mathrm{pg} / \mathrm{mL}$, normal: 7.2-63.3 pg/mL). The pituitary MRI (Magnetic Resonance Imaging) examination found a 4.3/4.4/6.2mm left paramedian microadenoma. The persistence of hypercortisolism after adenomectomy required GKRS (Gamma Knife radiosurgery). Four months after radiosurgery, complete remission of the disease was achieved and it was maintained at the last evaluation. At present, the patient is 20 weeks pregnant.

Conclusions: Gamma Knife radiosurgery offers a high control rate of pituitary adenomas and a reasonable rate of remission of residual hypercortisolism after neurosurgical treatment. After surgery or GKRS, periodic monitoring is necessary for patients with $C D$ due to the risk of pituitary insufficiency or relapse.
\end{abstract}

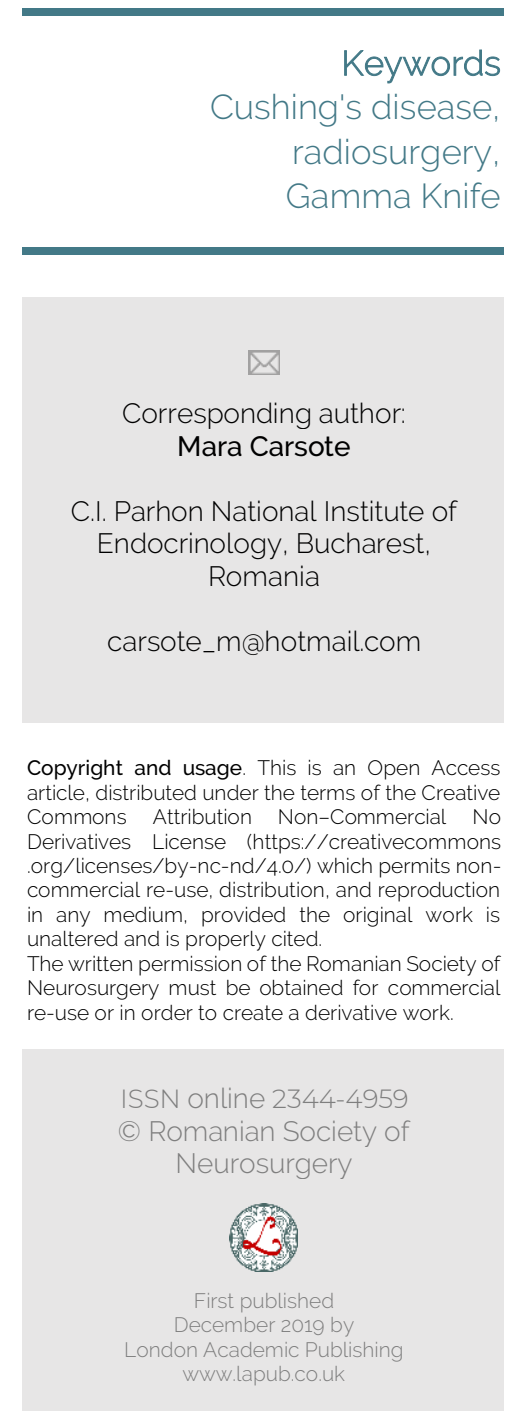




\section{INTRODUCTION}

Cushing's disease is a complex disorder, characterized by a series of symptoms such as central obesity, hypertension, diabetes, as well as psychiatric and neurocognitive changes, caused by an ACTH-secreting pituitary adenoma leading to cortisol hypersecretion [1].

The gold standard treatment for $C D$ is transsphenoidal surgical excision of the tumour, which is often curative.

However, there is a failure rate of 10 to $35 \%$ in reaching complete remission, while a proportion of patients also experience disease recurrence in time [2-6].

A second-line treatment used to achieve control of hypercortisolism is represented by targeted radiation of the sellar adenomatous tissue, the most reliable therapy being GKRS $[7,8]$.

\section{CASE PRESENTATION}

A 21-year-old female smoker, without significant past medical history, was admitted for weight gain of 20 $\mathrm{kg}$ in the past two months with centripetal distribution, transient headache, hair thinning, sleeping disorders and psycho-emotional lability. Clinical examination revealed height of $160 \mathrm{~cm}$, weight of $76 \mathrm{~kg}, \mathrm{BMI}$ (Body Mass Index) of 29.68 $\mathrm{kg} / \mathrm{m}^{2}$, blood pressure of $125 / 85 \mathrm{mmHg}$, heart rate of $64 \mathrm{bpm}$, round facies, acne, purple-red striae and hirsutism with a Ferriman-Gallwey score of 20. The hormonal profile showed high serum cortisol levels of $283.1 \mathrm{ng} / \mathrm{mL}$ (normal: 70-225 ng/mL) with maintained circadian rhythm, high 24-hour urine free cortisol (UFC) of $456.61 \mu \mathrm{g} / 24 \mathrm{~h}$ (normal: $50-190$ $\mu \mathrm{g} / 24 \mathrm{~h}$ ), non-suppression of cortisol after the $1 \mathrm{mg}$ DXM (dexamethasone) suppression test (of 145.9 $\mathrm{ng} / \mathrm{mL}$, normal $<18 \mathrm{ng} / \mathrm{mL}$ ), adequate suppression after the two-day, $8 \mathrm{mg}$ DXM test, high ACTH level of $260.6 \mathrm{pg} / \mathrm{mL}$ (normal: 7.2-63.3 pg/mL), high levels of DHEAS (Dehydroepiandrosterone-sulfate) and testosterone (Table 1). Pituitary function tests showed normal plasma gonadotropin levels, normal PRL (prolactin) and TSH (Thyroid Stimulating Hormone) of $0.51 \mu \mathrm{UI} / \mathrm{mL}$ with low FT4 (Free Thyroxine) of $0.86 \mathrm{ng} / \mathrm{dL}$ (normal: 0.89-1.76 ng/dL). There were no changes in biochemical parameters. Pituitary MRI (Magnetic Resonance Imaging) examination described a left paramedian microadenoma of 4.3/4.4/6.2 $\mathrm{mm}$ in diameter. Treatment with $25 \mu \mathrm{g}$ tyroxine daily was initiated. Transsphenoidal adenomectomy was performed one month later. A massive intraoperative haemorrhage did not allow the removal of the tumour, therefore GKRS at a dose of 25 Gy was performed three weeks later. Four months after radiosurgery, complete remission of the disease was achieved, which was maintained at the one-year post-radiosurgery evaluation (Tabel 1). MRI revealed the cystic transformation of the pituitary microadenoma. At present, the patient is 20 weeks pregnant.

\begin{tabular}{|c|c|c|c|c|}
\hline Parameter & Before surgery & After radiosurgery & Normal limits & Units \\
\hline $\begin{array}{l}\text { Morning plasma } \\
\text { cortisol }\end{array}$ & 283.1 & 176.2 & $70-225$ & $\mathrm{ng} / \mathrm{mL}$ \\
\hline Plasma cortisol $11 \mathrm{pm}$ & 148.9 & 74.9 & $50-165$ & $\mathrm{ng} / \mathrm{mL}$ \\
\hline 24-h urinary cortisol & 456.61 & 52.8 & $50-190$ & $\mu \mathrm{g} / 24 \mathrm{~h}$ \\
\hline ACTH & 260.6 & 43.14 & $7.2-63.3$ & $\mathrm{pg} / \mathrm{mL}$ \\
\hline $\begin{array}{c}\text { Morning plasma } \\
\text { cortisol* }^{*}\end{array}$ & 145.9 & 9.1 & $<18$ & $\mathrm{ng} / \mathrm{mL}$ \\
\hline $\begin{array}{c}\text { Morning plasma } \\
\text { cortisol** }\end{array}$ & 94.7 & & 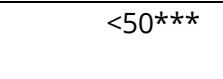 & $\mathrm{ng} / \mathrm{mL}$ \\
\hline DHEA-S & 8.19 & 2.79 & $0.9-3.6$ & $\mu g / m L$ \\
\hline Testosterone & 1.22 & 0.66 & $0.3-1$ & $\mathrm{ng} / \mathrm{dL}$ \\
\hline $\mathrm{TSH}$ & 0.51 & $0.297 * \star \star \star *$ & $0.4-4$ & $\mu \mathrm{UI} / \mathrm{mL}$ \\
\hline FT4 & 0.86 & 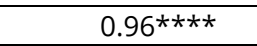 & $0.89-1.76$ & $\mathrm{ng} / \mathrm{dL}$ \\
\hline
\end{tabular}

Table 1: The endocrine parameters of a 21 -year-old female patient diagnosed with Cushing's disease: before surgery and postGamma Knife radiosurgery. *after the $1 \mathrm{mg}$ overnight Dexamethasone suppression test; **after the two-day, 8 mg Dexamethasone suppression test; ${ }^{* \star}$ more than50\% reduction; 24-h= 24-hours; ACTH= Adrenocorticotropic Hormone; DHEA-S=

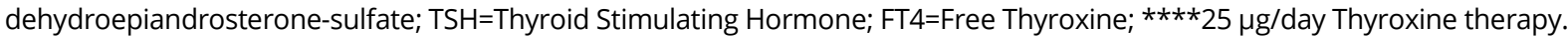




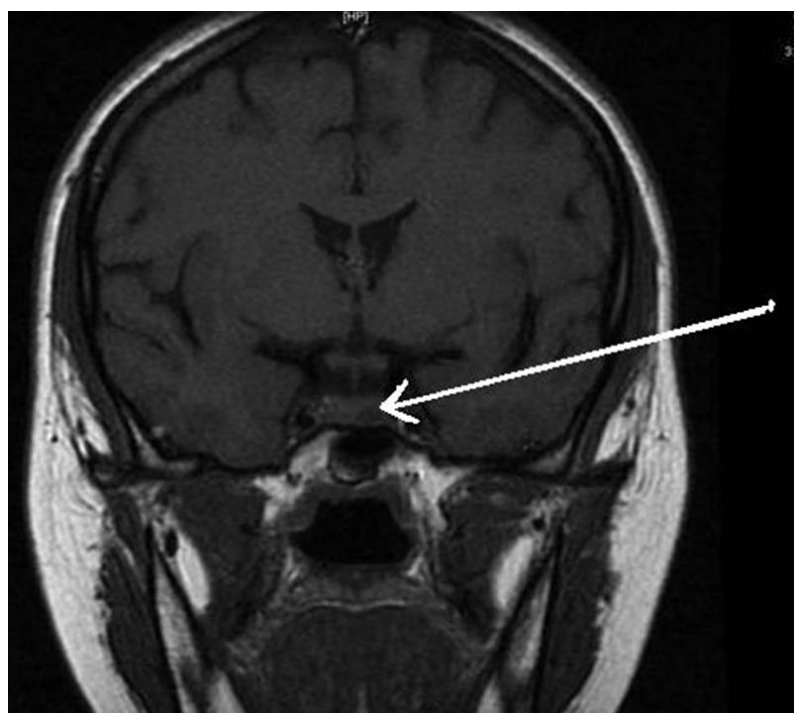

Figure 1: Preoperative contrast-enhanced pituitary MRI of a 21year-old woman diagnosed with Cushing's disease: microadenoma measuring $4 / 6.5 \mathrm{~mm}$. Coronal plane.

\section{DISCUSSIONS}

Cushing's disease remains a challenge in clinical practice, both in terms of diagnosis and treatment, especially for young patients [9-12]. Transsphenoidal adenomectomy, the first-line therapeutic option, is not always curative. Consequently, all patients should be informed that recurrence can occur in a delayed fashion and that annual endocrine testing should be done to track and confirm disease status [11-13]. In our patient's case, the failure of transsphenoidal adenomectomy was due to an intraoperative complication consisting of massive haemorrhage in the nasal mucosa. Considering the age of the patient and the desire to obtain a pregnancy, GKRS was recommended. The low risk of pituitary insufficiency and the relatively rapid remission of hypercortisolism are the main arguments for GKRS in persistent postoperative CD [14]. In this case, after GKRS, the secondary hypothyroidism persisted and was adequately controlled by thyroxine replacement therapy.

Generally, the secretor pituitary tumours are approached by neurosurgery, medical therapy in cases like acromegaly, prolactinoma (in this particular situation medical therapy is usually the first line), and Cushing's disease while radiotherapy remains a final option due to slow rate of response and the risk of associated hypopituitarism $[16,17,18]$. In this particular case the effect was rapidly observed. The non-secretor pituitary tumours are referred to surgery only if mass effect is positive $[19,20]$. As final option in Cushing's disease one time or two times bilateral adrenalectomy is done knowing the risk of lifelong adrenal insufficiency $[21,22]$.

Menstrual disorders and infertility are common in CD patients [15]. In our patient's case there were no changes in ovarian function before GKRS, except for a higher level of testosterone. The normalization of cortisol, testosterone and DEAS levels in less than 6 months after GKRS allowed spontaneous pregnancy. Considering the therapy used in this case, it is advisable to carefully monitor pituitary function throughout pregnancy.

\section{CONCLUSIONS}

Gamma Knife radiosurgery offers a high control rate of pituitary adenomas and a reasonable rate of remission of residual hypercortisolism after neurosurgical treatment. Close follow-up is necessary for patients with $C D$ due to the risk of possible relapse and pituitary insufficiency after surgery or GNRS.

Acknowledgements: There in no conflict of interest. We thank the patient for her consent.

\section{REFERENCES}

1. Mehta GU, Lonser RR. (2017). Management of hormonesecreting pituitary adenomas. Neuro-oncol, 19(6), 762-773.

2. Lonser RR, Wind JJ, Nieman LK, Weil RJ, DeVroom HL, Oldfield EH . (2013). Outcome of surgical treatment of 200 children with Cushing's disease. J Clin Endocrinol Metab, 98(3), 892-901.

3. Hofmann BM, Hlavac M, Martinez R, Buchfelder M, Müller OA, Fahlbusch R. (2008). Long-term results after microsurgery for Cushing disease: experience with 426 primary operations over 35 years. J Neurosurg, 108(1), 918.

4. Semple PL, Vance ML, Findling J, Laws ER. (2000). Transsphenoidal surgery for Cushing's disease: outcome in patients with a normal magnetic resonance imaging scan. Neurosurgery, 46(3), 553-558.

5. Ciric I, Zhao JC, Du H, Findling JW, Molitch ME, Weiss RE, Refetoff S, Kerr WD, Meyer J. (2012). Transsphenoidal surgery for Cushing disease: experience with 136 patients. Neurosurgery, 70(1), 70-81.

6. Rutkowski MJ, Breshears JD, Kunwar S, Aghi MK, Blevins LS. (2018). Approach to the postoperative patient with Cushing's disease. Pituitary, 18(2), 232-7.

7. Beauregard C, Dickstein G, Lacroix A. (2002). Classic and 
recent etiologies of Cushing's syndrome: diagnosis and therapy. Treat Endocrinol, 1(2), 79-94.

8. Sheehan JP, Xu Z, Salvetti DJ, Schmitt PJ, Vance ML. (2013). Results of gamma knife surgery for Cushing's disease, J Neurosurg, 119(6), 1486-1492.

9. Chen JC, Amar AP, Choi S, Singer P, Couldwell WT, Weiss $\mathrm{MH}$. (2003). Trans-sphenoidal microsurgical treatment of Cushing disease: postoperative assessment of surgical efficacy by application of an overnight low-dose dexamethasone suppression test. J Neurosurg, 98(5), 967973.

10. Hammer GD, Tyrell JB, Lamborn KR, et al. (2004). Transsphenoidal microsurgery for Cushing's disease: initial outcome and long-term results. J Clin Endocrinol Metab, 89(12), 6348-6357.

11. Dallapiazza RF, Oldfield EH, Jane JA Jr. (2015). Surgical management of Cushing's disease. Pituitary, 18(2), 211216.

12. Raff H. (2013). Update on late-night salivary cortisol for the diagnosis of Cushing's syndrome: methodological considerations. Endocrine, 44(2), 346-9.

13. Petersenn S, Beckers A, Ferone D, van der Lely A, Bollerslev J, Boscaro M, et al. (2015). Therapy of endocrine disease: outcomes in patients with Cushing's disease undergoing transsphenoidal surgery: systematic review assessing criteria used to define remission and recurrence. Eur J Endocrinol, 172(6), R227-39.

14. Jagannathan J, Sheehan JP, Pouratian N, Laws ER, Steiner L, Vance ML. (2007). Gamma Knife surgery for Cushing's disease. J Neurosurg, 106(6), 980-7.

15. Paduraru DN, Albu SE, Carsote M, Valea A. (2016). Adrenal Cushing's syndrome in a female with ovarian cancer. Arch Balk Med Union, 51(3), 410-412.

16. Valea A, Ghervan C, Carsote M, Morar A, lacob I, Tomesc F, Pop DD, Georgescu C. (2015). Effects of combination therapy: somatostatin analogues and dopamine agonists on GH and IGF1 levels in acromegaly. Clujul Med, 88(3), 3103, DOI:10.15386/cjmed-435.

17. Valea A, Carsote M, Ghervan C, Georgescu C. (2015). Glycemic profile in patients with acromegaly treated with somatostatin analogue. J Med Life, 8 (Spec Issue), 82-6.

18. Poiana C, Chirita C, Carsote M, Hortopan D, Goldstein A. (2009). Galactocele and prolactinoma - a pathogenic association? Maturitas, 62(1), 98-102, DOI:10.1016/j. maturitas.2008.10.015.

19. Carsote M, Chirita C, Dumitrascu A, Hortopan D, Fica S, Poiana C. (2009). Pituitary incidentalomas - how often is too often? J Med Life, 2(1), 92-7.

20. Gheorghisan-Galateanu AA, Carsote M, Valea A. (2017). Incidentaloma: from general practice to specific endocrine frame. J Pak Med Assoc, 67(6), 917-922.

21. Poiană C, Chiriţă C, Carşote M, Hortopan D, loachim $D$, Corneci CM, Stănescu B. (2013). Adrenal and pituitary incidentalomas in a case of Cushing's syndrome. Chirurgia (Bucur), 108(6), 886-91

22. Paduraru DN, Nica A, Carsote M, Valea A. (2016) Adrenalectomy for Cushing's syndrome: do's and don'ts. J Med Life, 9(4), 334-341. 